\title{
Characterization of Rhizospheric Bacillus Strains SG36 and SG42 for Decolorization of Reactive Yellow 2 Dye and Vigna radiata Growth Promotion in Dye Contaminated Soil
}

\author{
Yasir Bilal $^{1}$, Muhammad Shahid ${ }^{2}$, Faisal Mahmood ${ }^{1}$, Tanvir Shahzad ${ }^{1}$ and Sabir Hussain ${ }^{1 *}$ \\ ${ }^{1}$ Department of Environmental Sciences \& Engineering, Government College University Faisalabad, Pakistan \\ ${ }^{2}$ Department of Bioinformatics \& Biotechnology, Government College University Faisalabad, Pakistan \\ *For correspondence: sabirghani@gmail.com \\ Received 21 April 2021; Accepted 10 June 2021; Published 30 January 2022
}

\begin{abstract}
Contamination of agricultural soils with textile wastewaters loaded with synthetic dyes is one of the emerging issues because the presence of dyes in the soils not only affects the biological characteristics of the soils but also the germination and productivity of agricultural crops. The present study reports the characterization of two multifunctional bacterial strains Bacillus sp. SG36 and Bacillus sp. SG42, which have the potential not to promote the growth of plants in soil under stress due to reactive yellow 2 (RY2) dye but also the capability to cope with this dye through its decolorization. The strains were isolated from a rhizospheric soil repeatedly contaminated with colored textile wastewaters. Both the strains had optimal RY2 decolorization potential at slightly alkaline $\mathrm{pH}(7.5)$ and even in the presence of significant amount of $\mathrm{NaCl}\left(50 \mathrm{~g} \mathrm{~L}^{-1}\right)$ in the medium. The strains harbor the phosphorus solubilization and indole acetic acid production potentials in concurrence with decolorization of RY2. In a pot experiment, the strains SG36 and SG42 were found to significantly promote the growth (Shoot/root length, shoot/root fresh weight) of mung bean (Vigna radiate) in non-contaminated and RY2 contaminated soils in parallel with RY2 decolorization in the soil. (C) 2022 Friends Science Publishers
\end{abstract}

Keyword: Bacillus spp.; Dyes decolorization; PGPR; IAA Production; Phosphorus solubilization; Vigna radiata

\section{Introduction}

Among the most water consuming industries, textile industry is one of them. For manufacturing of one kilogram textile product, approximately 125 to $150 \mathrm{~L}$ water is used. But with this large use of water, it also produces large amount of wastewaters, which are often loaded with synthetic dyes and metal ions with different concentrations depending on type of dye molecule (Cervantes and Dos Santos 2011; Imran et al. 2015). The effluents originating from dyeing units of textile industries have been reported to harbor the dye concentrations ranging from 10 to $250 \mathrm{mg} \mathrm{L}^{-1}$ (Imran et al. 2015; O'Neill et al. 2017). According to Pierce (1994), maximum reported concentration of dyes is $1500 \mathrm{mg} / \mathrm{L}$. Annually about 280,000 tons of dyes are released in textile effluents worldwide out of which a major portion is contributed by the azo dyes (Jin et al. 2007; Imran et al. 2015). Among all the classes of synthetic dyes, azo dyes are an important class (Imran et al. 2015). Azo dyes are ring structured aromatic compounds and their structures have one or more than one azo groups $(-\mathrm{N} \equiv \mathrm{N}-)$ (Tripathi and Srivastava 2011). These dyes have been used in various industrial processes including the textile dyeing. Azo dyes comprise about $80 \%$ of the total synthetic dyes and their annual production has been reported as high as $7 \times 10^{5}$ tons (Fu and Viraraghavan 2001; Chacko and Subramaniam 2011). Due to its availability in variety of colors and brighter than other dyes that can easily be used with minimum consumption of energy, these dyes are used in more amount (Shah et al. 2014).

Unbound azo dyes are released into environment along with the wastewater, which contaminate the soil and water resources (Hasanbeigi and Price 2015; Imran et al. 2015). In water resources, they produce unpleasant odor and reduce the light penetration in water bodies which results in reduction of photosynthesis by hydrophytes (Roy et al. 2010; Imran et al. 2015; Imran et al. 2019). Many azo dyes inhibit the transfer of oxygen and increase the chemical oxygen demand (COD) (Lade et al. 2012; Imran et al. 2015). Some dyes and their compounds also affect the animals and human beings because they are not only carcinogenic and mutagenic but also cause different other diseases (Carneiro et al. 2010; Garzón-Zúñiga et al. 2011; Imran et al. 2015). Few scientists have stated that, due to water shortage, the wastewaters are used to irrigate fodder agricultural fields, which results into deposition of dyes in the soils (Imran et al. 2015; Ahmed et

To cite this paper: Bilal Y, M Shahid, F Mahmood, T Shahzad, S Hussain (2022). Characterization of rhizospheric Bacillus strains SG36 and SG42 for decolorization of reactive yellow 2 dye and Vigna radiata growth promotion in dye contaminated soil Intl J Agric Biol 27:8-18 
al. 2016). Due to their persistent nature, dyes concentrations as high as $456 \mathrm{mg} \mathrm{kg}^{-1}$ have been reported in the soils (Imran et al. 2015). In agricultural soils, the dyes not only change the nutritional and biological properties of soils including the microbial communities and enzymatic activities but also affect the plants by reducing the germination and biomass production in plants (Saratale et al. 2009; Ayed et al. 2011; Imran et al. 2016). As the existence of these persistent dyes in agricultural fields might be one of the threats for the future food security, there is need to devise the strategies for remediation of such dyes contaminated soils.

Some additional biotic activities are performed by many microbial populations such as promotion of the growth and yield of agricultural crops (Shahid et al. 2015; Akram et al. 2016). These plant growth promoting rhizobacteria (PGPR) enhance the phosphate solubilization, production of different plant growth promoting compounds (auxin, cytokinins, gibberellins, abcisic acid and ethylene) and ACC deaminase activity etc., which resultantly increase the plant growth (Shahid et al. 2012; Shahid et al. 2015; Akram et al. 2016; Syed-Ab-Rahman et al. 2019). Among different groups of microbes which play role in improvement of plant growth, phosphate solubilizing etc., are amongst those groups which are widely studied due to their ability to increase the bioavailability of phosphorus (P) in soil (Baig et al. 2014; Shahid et al. 2015; Syed-Ab-Rahman et al. 2019). These PSM enhance bioavailable soil $\mathrm{P}$ by different mechanisms like synthesis of different organic acids, microbial respiration, proton extrusion and phosphatase activity (Jorquera et al. 2008). Despite that various PGPRs have been isolated and characterized for improvement of growth and yield of different agricultural crops (Shahid et al. 2015; Akram et al. 2016; Syed-Ab-Rahman et al. 2019; Maqsood et al. 2021). However, during the recent years, some of the studies have reported few multifunctional PGPRs which not only improve the plant growth characteristics but also have concurrent potential to cope with different types of contaminants in the soil (Dwivedi et al. 2011; Mahmood et al. 2017; Maqbool et al. 2018; Kotoky et al. 2019). Dwivedi et al. (2011) reported a bacterial strain Pseudomonas aeruginosa JS11, which harbored the capability not only to degrade a herbicide, isoproturon, but also harbored the biocontrol and plant growth promoting characteristics. Likewise, Mahmood et al. (2017) isolated a Bacillus sp. SR2-1/1 harboring the plant growth promoting traits along with concurrent capability to decolorize different azo dyes. Likewise, Kotoky et al. (2019) reported a bacterial strain Serratia marcescens S2I7, which was found to resist the cadmium $(\mathrm{Cd})$ in the soil and improve the germination and growth of rice in a $(\mathrm{Cd})$ contaminated soil. One of the key advantages of such multifunctional PGPRs is that they can be exploited not only to promote the growth of the agricultural crops in contaminated soils but also to cope with the stress by removing or degrading the contaminants in such soils.

Contamination of agricultural soils with synthetic dyes due to irrigation with different types of wastewaters is one of the threats for the growth and yield of agricultural crops as well as sustainable food security. One of the ways to cope with this threat might be the exploitation of such microbial bioresources, which have the plant growth promoting potential in such contaminated soils as well as the concurrent ability to remediate the dyes. Hence, this research was conducted for isolation and characterization of multifunctional bacterial strains that have capacity to biodecolorize different azo dyes and also have the plant growth promoting characteristics under stress due to dyes.

\section{Materials and Methods}

\section{Chemicals and media}

The reagents and chemicals which were used in this study, were of analytical grade and procured from Sigma Aldrich. General characteristics and molecular formula of the dyes are presented (described) in Table 1. Mineral salt medium (MSM) was used for the bacterial isolation with the capability of decolorization of reactive yellow-2 (RY2) and other dyes. MSM contained $\mathrm{MgSO}_{4} .7 \mathrm{H}_{2} \mathrm{O}\left(0.5 \mathrm{~g} \mathrm{~L}^{-1}\right), \mathrm{NaCl}\left(50.0 \mathrm{~g} \mathrm{~L}^{-1}\right)$, $\mathrm{CaCl}_{2} .2 \mathrm{H}_{2} \mathrm{O}\left(0.1 \mathrm{~g} \mathrm{~L}^{-1}\right), \mathrm{KH}_{2} \mathrm{PO}_{4}\left(1.0 \mathrm{~g} \mathrm{~L}^{-1}\right)$, yeast extract $\left(4.0 \mathrm{~g} \mathrm{~L}^{-1}\right), \mathrm{Na}_{2} \mathrm{HPO}_{4}\left(1.0 \mathrm{~g} \mathrm{~L}^{-1}\right)$, and agar $\left(15.0 \mathrm{~g} \mathrm{~L}^{-1}\right.$ in case of solid medium). For the determination of metal tolerance of bacterial strains, nutrient agar (NA) medium was used. If there was need to maintain the $\mathrm{pH}$ of the solution, then standard $\mathrm{NaOH}$ or $\mathrm{HCl}$ were used.

\section{Isolation of dye decoloring bacteria}

Dye decolorizing bacteria was isolated from a textile wastewater contaminated rhizospheric soil using MSM spiked with $150 \mathrm{mg} \mathrm{L}^{-1}$ of RY2 dye. For this purpose, $1.0 \mathrm{~g}$ of the contaminated rhizospheric soil was added in $19 \mathrm{~mL}$ of the MSM spiked with RY2 in a test tube. The inoculated test tube was tightly capped and incubated under static condition in dark at $25^{\circ} \mathrm{C}$ along with an un-inoculated control without the soil. The samples were taken from each tube after regular intervals of time and centrifuged (6000 rpm for $10 \mathrm{~min}$ ). The supernatant was used to analyze the decolorization at $404 \mathrm{~nm}$ through a UV-Visible Spectrophotometer (Stalwart STA$8200 \mathrm{UV} / \mathrm{VIS}$ ) and the formula used for the estimation of decolorization (\%) is mentioned below:

$$
\text { Decolorization }(\%)=\frac{X-Y}{X} \times 100
$$

Where $\mathrm{X}$ is the absorbance reading of uninoculated control and $\mathrm{Y}$ is the absorbance reading of inoculated sample.

When the initially added dye was decolorized by more than $50 \%$ then $1.0 \mathrm{~mL}$ from this culture was further inoculated in $19 \mathrm{~mL}$ of fresh MSM spiked with RY2, incubated under similar condition and decolorization was monitored as already described above. After repeating the process of enrichment for five times, $10^{-3}$ to $10^{-6}$ dilutions of the final enriched culture were spread on MSM agar media 
plates. After four days, 55 fast growing colonies having relatively varying growth pattern were picked and purified through repeated streaking on MSM agar media plates. The purified 55 isolates were tested for their potential to solubilize phosphorus on NBRIP agar media plates as already described by Baig et al. (2014). These isolates having the potential for $\mathrm{P}$ solubilization were suspended in MSM separately, allowed to grow under shaking $(125 \mathrm{rpm})$ for $24 \mathrm{~h}$ and then their optical density $\left(\mathrm{OD}_{600}\right)$ was maintained at 0.5 . One $\mathrm{mL}$ from each of the freshly prepared cultures of the P solubilizing isolates was separately inoculated in $9.0 \mathrm{~mL}$ of MSM spiked with $150 \mathrm{mg} \mathrm{L}^{-1}$ of YR2 to obtain optical density $\left(\mathrm{OD}_{600}\right)$ of 0.05 , tightly sealed and incubated at $25^{\circ} \mathrm{C}$ under static conditions. After $24 \mathrm{~h}$, decolorization of RY2 by each isolate was determined using UV-Visible spectrophotometer analysis as already described above. Out of these isolates, two isolates SG36 and SG42 showing the maximum RY2 decolorization (\%) were chosen for further study. The purity of the isolates SG36 and SG42 was verified through repeated streaking on MSM agar plates. The cultures of SG36 and SG42 were preserved at $4^{\circ} \mathrm{C}$ as well as $-20^{\circ} \mathrm{C}$ (Glycerol stocks) for further experiments.

\section{Identification of the isolates SG36 and SG42}

The sequences of $16 \mathrm{~S}$ rRNA of SG36 and SG42 were amplified by using the protocol described by Hussain et al. (2013). These amplified products were sequenced by Macrogen (Seoul, Korea). After sequencing, these sequences of SG36 and SG42 were compared with known nucleotide sequences in BlastN library. The construction of phylogenetic tree and processing of data by neighbor joining method was done as described by Hussain et al. (2013). These sequences were deposited in the GeneBank under accession numbers MW931776 (SG36) and MW931777 (SG42).

\section{Physiological characterization of the strains SG36 and SG42}

Decolorization of various dyes by the strains SG36 and SG42: The capacity of strains SG36 and SG42 to decolorize the various azo dyes i.e., RR-120, RY-2, DB-19, RO-16, RB5, DR-28, BD-71 and DY-50 was tested in MSM. For this purpose, the cells of the strains SG36 and SG42 were harvested from their respective cultures grown in MSM media. Three sets of freshly prepared MSM test tubes spiked with $150 \mathrm{mg} \mathrm{L}^{-1}$ of each azo dye was prepared separately. One set of the tubes was inoculated with the strain SG36 to develop an optical density $\left(\mathrm{OD}_{600}\right)$ value of 0.05 . The second set of the tubes was inoculated with the strain SG42 to develop an optical density $\left(\mathrm{OD}_{600}\right)$ value of 0.05 . The third set was control without any inoculation. The triplicate experiment was incubated at $30^{\circ} \mathrm{C}$ in dark under static conditions. Over the incubation periods of 48 and $96 \mathrm{~h}$, the samples were taken from each tube and centrifuged at 6000 rpm for $5 \mathrm{~min}$. The supernatants of all dyes were analyzed through UV-Visible spectrophotometer at their respective wavelengths $\left(\lambda_{\max }\right)$ given in Table 1 and decolorization $(\%)$ of each dye was calculated.

Decolorization of RY2 by the strains SG36 and SG42 at different pH values: Reactive yellow 2 decolorization efficiency of the strains SG36 and SG42 was determined at different $\mathrm{pH}$ levels (5.5-9.5). Different $\mathrm{pH}$ levels of the MS media were adjusted by using standard $\mathrm{HCl}$ or $\mathrm{NaOH}$. The cells of the strains SG36 and SG42 were harvested in the same way as already described in previous sections and inoculated in MSM containing RY2 $\left(150 \mathrm{mg} \mathrm{L}^{-1}\right)$ at different $\mathrm{pH}$ values. The experiment was incubated under similar conditions and aliquots were collected for RY2 decolorization at different time intervals over the incubation. Decolorization (\%) of RY2 was estimated by analyzing it through UV-Visible Spectrophotometer as described above. Over $24 \mathrm{~h}$ of incubation, the aliquots were also collected for estimation of growth of the strains SG36 and SG42. For this purpose, the samples were taken from each tube and centrifuged (6000 rpm for $5 \mathrm{~min}$ ), the pellets were washed thrice with distilled water and re-suspended in equal volume of the distilled water. The growth $\left(\mathrm{OD}_{600}\right)$ was monitored by taking the absorbance of the suspended cells at $600 \mathrm{~nm}$. This data were used to find out the correlation between the growth $\left(\mathrm{OD}_{600}\right)$ of the strains with their respective RY2 decolorization (\%) values over $24 \mathrm{~h}$ incubation.

Decolorization of RY2 by the strains in the presence of different $\mathrm{NaCl}$ concentrations: Reactive yellow 2 decolorization efficiency of the strains SG36 and SG42 was also estimated in the presence of different levels $(0,10,20$, 50,100 and $150 \mathrm{~g} \mathrm{~L}^{-1}$ ) of $\mathrm{NaCl}$ in the MS medium. The cells of the strains SG36 and SG42 were harvested in the same way as already described in previous sections and inoculated in MS media containing RY2 (150 $\left.\mathrm{mg} \mathrm{L}^{-1}\right)$ along with different levels $\left(0,10,20,50,100\right.$ and $\left.150 \mathrm{~g} \mathrm{~L}^{-1}\right)$ of $\mathrm{NaCl}$. The experiment was incubated under similar conditions and aliquots were collected for RY2 decolorization at different time intervals over the incubation period. Decolorization (\%) of RY2 was estimated by analyzing it through UV-Visible Spectrophotometer as already described above. Over 24, 48 and $72 \mathrm{~h}$ of incubation, the aliquots were also collected for estimation of growth of the strains SG36 and SG42. For this purpose, the aliquot parts were centrifuged (6000 rpm for 5 minutes), the pellets were washed thrice with distilled water and resuspended in equal volume of the distilled water. The growth $\left(\mathrm{OD}_{600}\right)$ was monitored by taking the absorbance of the suspended cells at $600 \mathrm{~nm}$. These data were used to find the correlation between the growth $\left(\mathrm{OD}_{600}\right)$ of the strains with their respective RY2 decolorization (\%) values over 24,48 and $72 \mathrm{~h}$ incubation.

Heavy metal tolerance of the strains SG36 and SG42: Heavy metal tolerance of the strains SG36 and SG42 was estimated in terms of minimum inhibitory concentration (MIC) of the metal ions $\left(\mathrm{Cd}^{2+}, \mathrm{Ni}^{2+}, \mathrm{Pb}^{2+}, \mathrm{Zn}^{2+}, \mathrm{Cr}^{6+}, \mathrm{Co}^{2+}\right)$ for the growth of the strains SG36 and SG42. For estimation 
of MIC, different levels ( 1 to $35 \mathrm{mM}$ ) of the individual metal ions $\mathrm{Cd}^{2+}, \mathrm{Ni}^{2+}, \mathrm{Pb}^{2+}, \mathrm{Zn}^{2+}, \mathrm{Cr}^{6+}, \mathrm{Co}^{2+}$ were separately spiked in nutrient agar media using their respective salts $\left(\mathrm{CdCl}_{2}\right.$, $\left.\mathrm{NiCl}_{2} \cdot 6 \mathrm{H}_{2} \mathrm{O}, \mathrm{Pb}\left(\mathrm{NO}_{3}\right)_{2}, \mathrm{ZnSO}_{4}, \mathrm{~K}_{2} \mathrm{Cr}_{2} \mathrm{O}_{7}, \mathrm{Co}\left(\mathrm{NO}_{3}\right)_{2}\right)$. The agar media plates containing different metal ions were inoculated separately with the strains SG36 and SG42. The inoculated plates were incubated at $28 \pm 2^{\circ} \mathrm{C}$ for 7 days. After incubation, the concentration of the individual metal ions resulting in inhibition of the growth of the strains SG36 and SG42 was considered as MIC.

\section{Estimation of plant growth promoting characteristics of the strains SG36 and SG42}

Estimation of phosphorus solubilization by the strains SG36 and SG42: P solubilization potential of SG36 and SG42 was estimated qualitatively in Pikovskaya's agar media plates (Pikovskaya 1948). For this purpose, the spot inoculation of pure cultures of the strains SG36 and SG-42 was done on separate Pikovskaya's agar media plates and incubated in dark at $28 \pm 2^{\circ} \mathrm{C}$ (Pikovskaya 1948). $\mathrm{P}$ solubilizing capability of the strains was estimated by formation of halo zones on media. The amount of $\mathrm{P}$ solubilization by strains was also estimated calorimetrically by inoculating the pure cultures of SG36 and SG-42 in 500mL Pikovskaya's broth $\left(150 \mathrm{mg} \mathrm{L}^{-1}\right)$ in Erlenmeyer flasks. These flasks were incubated in orbital shaker at $150 \mathrm{rpm}$, $28 \pm 2^{\circ} \mathrm{C}$. A sample possessing $20-\mathrm{mL}$ was harvested and centrifuged $(13,000 \mathrm{~g}$ for $10 \mathrm{~min})$ to collect the supernatant from each flask. Phosphomolybdate blue color method was used to measure the $\mathrm{P}$ solubilization in culture supernatant (Murphy and Riley 1962) using spectrophotometer (STALWART STA-8200V UV/VIS) at $882 \mathrm{~nm}$. During the incubation time, the $\mathrm{pH}$ of the medium was also measured at different intervals of time. At the end of the incubation, decolorization of RY2 was also estimated as described above.

Estimation of IAA production by the strains SG36 and SG42: Indole 3-acetic acid production potential of selected strain SG36 and SG42 was estimated by procedure introduced by Gordon and Weber (1951). Pure cultures of SG36 and SG42 were separately inoculated in $100 \mathrm{ml}$ nutrient broth spiked with RY2 (150 $\left.\mathrm{mg} \mathrm{L}^{-1}\right)$ and containing $100 \mathrm{mg} \mathrm{L}^{-1}$ tryptophan. These cultures were grownup on an orbital shaker $(150 \mathrm{rpm})$ at $28 \pm 2^{\circ} \mathrm{C}$ for $48 \mathrm{~h}$. The cultures were harvested by centrifugation at $13000 \mathrm{~g}$ for $5 \mathrm{~min} .2 \mathrm{~mL}$ Salkoweski's reagent was added as a color developing reagent in $1 \mathrm{~mL}$ cultures of the strain SG36 and SG42 separately. These samples were kept in dark for development of color for 30 mins. The quantity of IAA production was measured through spectrophotometer at $540 \mathrm{~nm}$. The standard IAA solution $(0,5,10,50,100,200$ or $500 \mu \mathrm{g} \mathrm{mL}$ ${ }^{1}$ ) were used for standard curve. Over the incubation, the $\mathrm{pH}$ of the medium was also measured at different intervals of time. At the end of the incubation, decolorization of RY2 was also estimated as already described above.
Potential of the strains SG36 and SG42 for plant growth promotion of Vigna radiata under RY2 stress: The strains SG36 and SG42 were also evaluated for their potential to concurrently remove RY2 and promote growth of $V$. radiata in a soil spiked with RY2 (500 $\left.\mathrm{mg} \mathrm{kg}^{-1}\right)$. For this purpose, a loam soil never contaminated with textile dyes having the $\mathrm{pH}$ value of 7.85 and electrical conductivity value of $0.49 \mathrm{dS} \mathrm{m}$

${ }^{1}$ was used. The soil was distributed in two parts. A part of the soil was spiked with RY2 solution to a final concentration of $500 \mathrm{mg} \mathrm{Kg}^{-1}$ of RY2 in the soil and homogenized by thorough mixing (contaminated soil). The second part of the soil was spiked with equal volume of distilled water (noncontaminated soil). The contaminated soil was further divided in three portions. One portion of the contaminated soil was inoculated with the strain SG36 to a final estimated population of $10^{7} \mathrm{CFU} \mathrm{\textrm {g } ^ { - 1 }}$ of soil. Similarly, the second portion of the contaminated soil was inoculated with equal population of the strain SG42, whereas the third portion was left un-inoculated. The non-contaminated soil was also divided in three portions and inoculated with the strains SG36 and SG42 in the same way as already done for the contaminated soil. The inoculated contaminated and noncontaminated soils along with their respective un-inoculated controls were put in three replicates of small pots and incubated under maintained moisture levels for 10 days following a completely randomized design. After 10 days, seven seeds of mung bean were sown in each pot which were maintained to four plants per pot after the germination. The plants were allowed to grow for 30 days and then harvested for estimation of their shoot fresh weight ( $\mathrm{g} / \mathrm{plant})$, shoot length $(\mathrm{cm})$, root length $(\mathrm{cm})$, root fresh weight $(\mathrm{g} / \mathrm{plant})$. At the end of the study, the remaining RY2 was extracted and estimated from the soil samples following the protocol reported by Imran et al. (2015).

\section{Statistical analysis}

The shoot length and shoot weight data were statistically analyzed by Tukey's HSD Test after the analysis of variance (ANOVA) at $p<0.05$ using Statistix version 8.1.

\section{Results}

\section{Isolation and Identification of the strains SG36 and SG42}

While estimating the potential of the isolates for RY2 decolorization it was observed that the decolorization (\%) of RY2 by these isolates ranged from $2.4 \%$ to $95.6 \%$ of the initially added RY2 after $24 \mathrm{~h}$ in comparison to the uninoculated control. Over this incubation period, the highest decolorization $(95.6 \%)$ of RY2 was carried out by the strain SG36 followed by the strain SG42 which decolorized $83.2 \%$ of added RY2 dye. BlastN analysis of $16 \mathrm{~S}$ rDNA sequences indicated that the maximum similarity was shown by the strains SG36 and SG42 with the genus Bacillus sp. The phylogenetic tree based on neighbor joining method also 
Table 1: Characteristics of the synthetic dyes used in this study

\begin{tabular}{|c|c|c|c|c|}
\hline Azo dyes & Molecular formula & Molecular weight & Color index number & $\lambda_{\max }$ \\
\hline Reactive Yellow-2 & $\mathrm{C}_{25} \mathrm{H}_{15} \mathrm{C}_{13} \mathrm{~N}_{9} \mathrm{Na}_{3} \mathrm{O}_{10} \mathrm{~S}_{3}$ & 872.96 & 18972 & 404 \\
\hline Reactive Red-120 & $\mathrm{C}_{44} \mathrm{C}_{12} \mathrm{H}_{24} \mathrm{~N}_{14} \mathrm{Na}_{6} \mathrm{O}_{20} \mathrm{~S}_{6}$ & 1469.98 & & 535 \\
\hline Reactive Orange-16 & $\mathrm{C}_{20} \mathrm{H}_{17} \mathrm{~N}_{3} \mathrm{Na}_{2} \mathrm{O}_{11} \mathrm{~S}_{3}$ & 617.54 & 17757 & 494 \\
\hline Direct red-28 (Congo red) & $\mathrm{C}_{32} \mathrm{H}_{22} \mathrm{~N}_{6} \mathrm{Na}_{2} \mathrm{O}_{6} \mathrm{~S}_{2}$ & 696.66 & 22120 & 497 \\
\hline Direct black-19 & $\mathrm{C}_{34} \mathrm{H}_{27} \mathrm{~N}_{13} \mathrm{Na}_{2} \mathrm{O}_{7} \mathrm{~S}_{2}$ & 839.77 & & 520 \\
\hline Direct Blue-71 & $\mathrm{C}_{40} \mathrm{H}_{28} \mathrm{~N}_{7} \mathrm{Na}_{4} \mathrm{O}_{13} \mathrm{~S}_{4}$ & 965.94 & 34140 & 594 \\
\hline Direct Yellow-50 & $\mathrm{C}_{35} \mathrm{H}_{24} \mathrm{~N}_{6} \mathrm{Na}_{4} \mathrm{O}_{13} \mathrm{~S}_{4}$ & 956.82 & 29025 & 390 \\
\hline
\end{tabular}

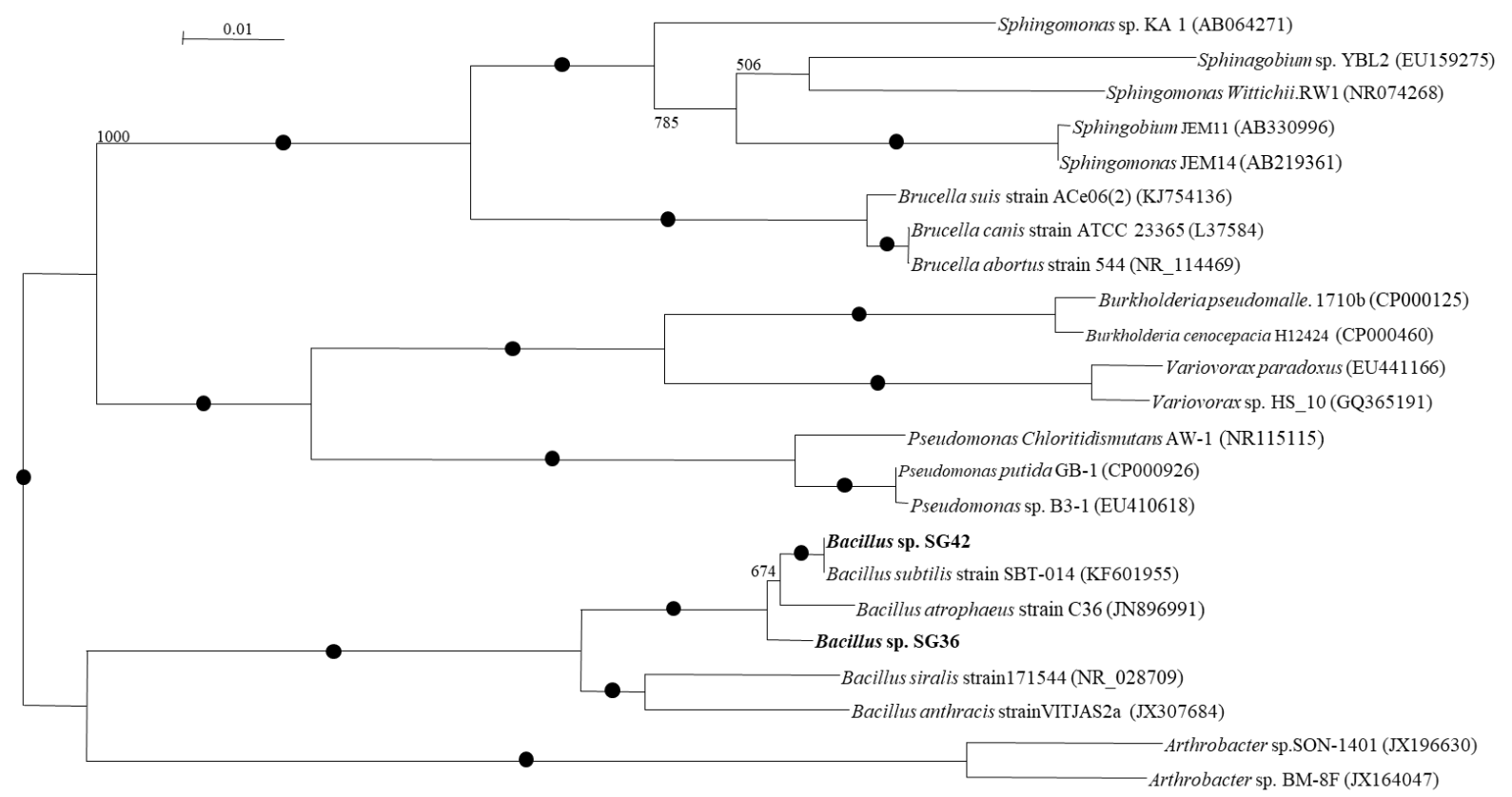

Fig. 1: Phylogenetic tree based on Neighbor Joining. The dye decolorizing strains isolated in the present study are shown as bold. The bootstrap values great than 900 are shown as black circles

confirmed that these strains belonged to the Bacillus sp. (Fig. 1). Hence, on the basis of BlastN and the phylogenetic analyses, the strains SG36 and SG42 were designated as Bacillus sp. SG36 and Bacillus sp. SG42, respectively.

\section{Decolorization of different azo dyes by the strains SG36 and SG42}

During the testing of decolorization of different azo dyes by the strain SG36 and SG42, while studying the decolorization of various azo dyes by the strains SG36 and SG42, it was observed that these strains had the potential to decolorize all the selected azo dyes but to variable extents (Table 2). It was observed that over $48 \mathrm{~h}$ incubation, 92.4, 47.4, 43.5, 91.2, $51.4,48.3,54.6$ and $12.1 \%$ of the initially added RY-2, RO16, RR_120, RB-5, DR-8, DB-19, DB-71 and DY-50, respectively, were decolorized by the strain SG36. Over the same incubation period (48 h), 89.1, 56.6, 46.2, 38.4, 32.4, $13.5,27$. and $34.6 \%$ of the initially added reactive RY-2, RO16, RR-120, RB-5, DR-28, DB-19, DB-71 and DY, respectively, were decolorized by the strain SG42. Over $96 \mathrm{~h}$ incubation period, the strain SG36 carried out the maximum decolorization of reactive black $5(97.3 \pm 1.1 \%)$ followed by the reactive yellow $2(95.3 \pm 1.7 \%)$ and the strain SG42 carried out the maximum decolorization of reactive yellow 2 $(97.2 \pm 1.2 \%)$ followed by the reactive black $5(89.17 \%)$ (Table 2).

\section{Decolorization of RY2 by SG36 and SG42 at different pH}

The varying $\mathrm{pH}$ values were found to affect the $\mathrm{RY} 2$ decolorization as well as the growth of the strains SG36 and SG42 (Fig. 2). The efficiency of strain SG36 to decolorize the RY2 was significantly affected by the $\mathrm{pH}$. Over $24 \mathrm{~h}$ of incubation, 32.5, 63.9, 82.9, 78.3 and $37.0 \%$ of RY2 was decolorized by SG36 at pH 5.5, 6.5, 7.5, 8.5 and 9.5, respectively (Fig. 2A). However, over $72 \mathrm{~h}$ incubation, $>90 \%$ RY2 was decolorized by the strain SG36 at pH 6.5, 7.5 and 8.5. At this incubation time, the strain SG36 decolorized 
Microbial Remediation of Soil Polluted with Synthetic Dyes / Intl J Agric Biol, Vol 27, No 1, 2022

Table 2: Decolorization of different azo-dyes by Bacillus sp. SG36 and Bacillus sp. SG42

\begin{tabular}{llccc}
\hline Dyes & & \multicolumn{3}{c}{ Decolorization (\%) } \\
\hline \\
Reactive Yellow-2 & $48 \mathrm{~h}$ & SG36 & SG42 \\
Reactive Red-120 & $96.4 \pm 3.5$ & $95.3 \pm 1.7$ & $89 \mathrm{~h}$ & $96 \mathrm{~h}$ \\
Reactive Orange-16 & $47.4 \pm 2.9$ & $75.4 \pm 1.6$ & $56.6 \pm 4.1$ & $97.2 \pm 1.2$ \\
Reactive Black-5 & $43.5 \pm 4.6$ & $69.0 \pm 2.9$ & $46.2 \pm 2.1$ & $62.2 \pm 2.5$ \\
Direct Red-28 & $91.2 \pm 1.2$ & $97.3 \pm 1.1$ & $38.4 \pm 3.6$ & $55.1 \pm 1.3$ \\
Direct Black-19 & $51.4 \pm 2.8$ & $70.2 \pm 1.4$ & $32.4 \pm 1.9$ & $89.5 \pm 1.7$ \\
Direct Blue-71 & $48.3 \pm 4.1$ & $68.0 \pm 2.3$ & $13.5 \pm 2.3$ & $41.2 \pm 2.2$ \\
Direct Yellow-50 & $54.6 \pm 3.3$ & $73.2 \pm 2.5$ & $27.6 \pm 3.5$ & $18.9 \pm 3.1$ \\
\end{tabular}

$82.6 \%$ and $85.5 \%$ of the initially added $\mathrm{RY} 2$ at $\mathrm{pH}$ values of 5.5 and 9.5 , respectively (Fig. 2A). Similarly, the $\mathrm{pH}$ was also found to have a significant effect on decolorization of RY2 by SG42 (Fig. 2B). Over $24 \mathrm{~h}$ incubation, 31.7, 77.3, 85.6, 64.5 and $27.6 \%$ of RY2 was decolorized by SG42 at pH 5.5, 6.5, 7.5, 8.5 and 9.5, respectively (Fig. 2B). However, over $72 \mathrm{~h}$ incubation, $>90 \%$ of RY2 was decolorized by SG42 at $\mathrm{pH} 6.5,7.5$ and 8.5. At this incubation time, the strain SG42 could decolorize 56.8 and $66.5 \%$ of RY2 at pH 5.5 and 9.5, respectively (Fig. 2B). Fig. 2C shows the correlation between the growth $\left(\mathrm{OD}_{600}\right)$ of the strains SG36 and SG42 and their respective $\mathrm{RY} 2$ decolorization (\%) at different $\mathrm{pH}$ values over an incubation period of $24 \mathrm{~h}$. The data based on regression correlation clearly showed that the growth as well as the decolorization of both strains at different $\mathrm{pH}$ values were significantly correlated with each other $\left(\mathrm{R}^{2}\right.$ values $\left.>0.9\right)$.

\section{Decolorization of RY2 by SG36 and SG42 in the presence of different $\mathrm{NaCl}$ contents}

Results showed that both the strains have the capacity to decolorize RY2 even at $100 \mathrm{~g} \mathrm{~L}^{-1}$ despite that the presence of $\mathrm{NaCl}$ was affecting the extent of decolorization. Over $24 \mathrm{~h}$ incubation, 77.3, 73.1, 54.9, 30.8, 22.7 and $15.9 \%$ of RY2 was decolorized by the strain SG36 in the media containing $0,10,20,50,100$ and 200 of $\mathrm{NaCl} \mathrm{g} \mathrm{L}^{-1}$, respectively (Fig. $3 \mathrm{~A})$. However, after $72 \mathrm{~h}$ of incubation, $>90 \% \mathrm{RY} 2$ was decolorized by $\mathrm{SG} 36$ in the presence of $\mathrm{NaCl}\left(50 \mathrm{~g} \mathrm{~L}^{-1}\right)$ in the medium. At this incubation time, the strain SG36 has decolorized 46.0 and $20.2 \%$ RY2 in the presence of 100 and $150 \mathrm{~g} \mathrm{~L}^{-1}$ of $\mathrm{NaCl}$ in the medium, respectively (Fig. 3A). Fig. $3 \mathrm{~B}$ indicates the efficiency of strain SG42 to decolorize the $\mathrm{RY} 2$ also affected significantly in the presence of $\mathrm{NaCl}$ in the media. After $24 \mathrm{~h}$ of incubation period, 57.1, 44.9, 40.4, 15.6, 13.2 and $10.7 \%$ of the added RY2 was decolorized by SG42 in the media containing $0,10,20,50,100$ and 200 of $\mathrm{NaCl} g$ $\mathrm{L}^{-1}$, respectively (Fig. 3B). Over $48 \mathrm{~h}$ incubation, 97.1, 89.8, $85.3,59.6,26.7$ and $12.1 \%$ of RY2 was decolorized by the strain SG42 in the media containing 0,10, 20, 50, 100 and 200 of $\mathrm{NaCl} \mathrm{g} \mathrm{L}^{-1}$, respectively (Fig. 3B). However, after 72 $\mathrm{h}$ of incubation, $>90 \%$ of the added RY 2 concentration was decolorized by the strain $\mathrm{SG} 42$ in the presence of $\mathrm{NaCl}(50 \mathrm{~g}$ $\left.\mathrm{L}^{-1}\right)$ in the medium. At this incubation time, the strain SG42 decolorized 47.1 and $23.2 \%$ RY2 in the presence of 100 and
$150 \mathrm{~g} \mathrm{~L}^{-1}$ of $\mathrm{NaCl}$ in the medium, respectively (Fig. 3B). Fig. $3 \mathrm{C}$ shows the regression correlation between the growth $\left(\mathrm{OD}_{600}\right)$ of the strains SG36 and SG42 and their respective $\mathrm{RY} 2$ decolorization in the presence of different $\mathrm{NaCl}$ levels in mineral salt media over an incubation periods of 24, 48 and $72 \mathrm{~h}$. The figure clearly shows that, at all three incubation times, the growth as well as the decolorization of both strains at different levels of $\mathrm{NaCl}$ were significantly correlated with each other $\left(\mathrm{R}^{2}\right.$ values $\left.>0.9\right)$.

\section{Metal tolerance of the strain SG36 and SG42}

While studying the metal ions tolerance of the bacterial strain SG36 and SG42 in terms of MIC of the metal ions, both the strains were observed to have varying levels of tolerance for different metal ions (Table 3). According to the results, the MIC values of $\mathrm{Zn}^{2+}, \mathrm{Pb}^{2+}, \mathrm{Cd}^{2+}, \mathrm{Co}^{2+}, \mathrm{Ni}^{2+}$ and $\mathrm{Cr}^{6+}$ against the strain SG36 were observed to be 7.65, 9.66, 8.90, 33.89, 8.52 and $21.15 \mathrm{mM}$ respectively (Table 3 ). However, the MIC values of $\mathrm{Zn}^{2+}, \mathrm{Pb}^{2+}, \mathrm{Cd}^{2+}, \mathrm{Co}^{2+}, \mathrm{Ni}^{2+}$ and $\mathrm{Cr}^{6+}$ against the strain SG42 were observed to be 9.94, 4.83, 8.45, 16.94, 9.37 and $28.85 \mathrm{mM}$, respectively (Table 3 ).

\section{Plant growth promoting characteristics of SG36 and SG42}

Both Bacillus spp. strains SG36 and SG42 indicated a good potential for phosphate solubilization (Fig. 4A). Over the incubation period $(240 \mathrm{~h})$, more than $700 \mu \mathrm{g} \mathrm{mL}^{-1}$ of $\mathrm{P}$ solubilization was observed by both of the bacterial strains. Over the incubation period, the $\mathrm{pH}$ of the media was observed to gradually decrease with the $\mathrm{pH}$ values of 4.8 and 5.1 in the media containing the strains SG36 and SG42, respectively (Fig. 4A). Similarly, both the strains were also observed to have a good potential for IAA production (Fig. 4B). Over the incubation period (168 h), 26.3 and $19.5 \mu \mathrm{g} \mathrm{mL}^{-1}$ of IAA was observed to be produced by the strains SG36 and SG42, respectively. Over the incubation period, the $\mathrm{pH}$ of the media was observed to gradually decrease with the $\mathrm{pH}$ values of 5.3 and 5.4 in the media containing the strains SG36 and SG42, respectively (Fig. 4B). In both the experiments, in parallel to the $\mathrm{P}$ solubilization and IAA production, almost complete $(>90 \%)$ decolorization of RY2 by both the strains SG36 and SG42 was also observed. 

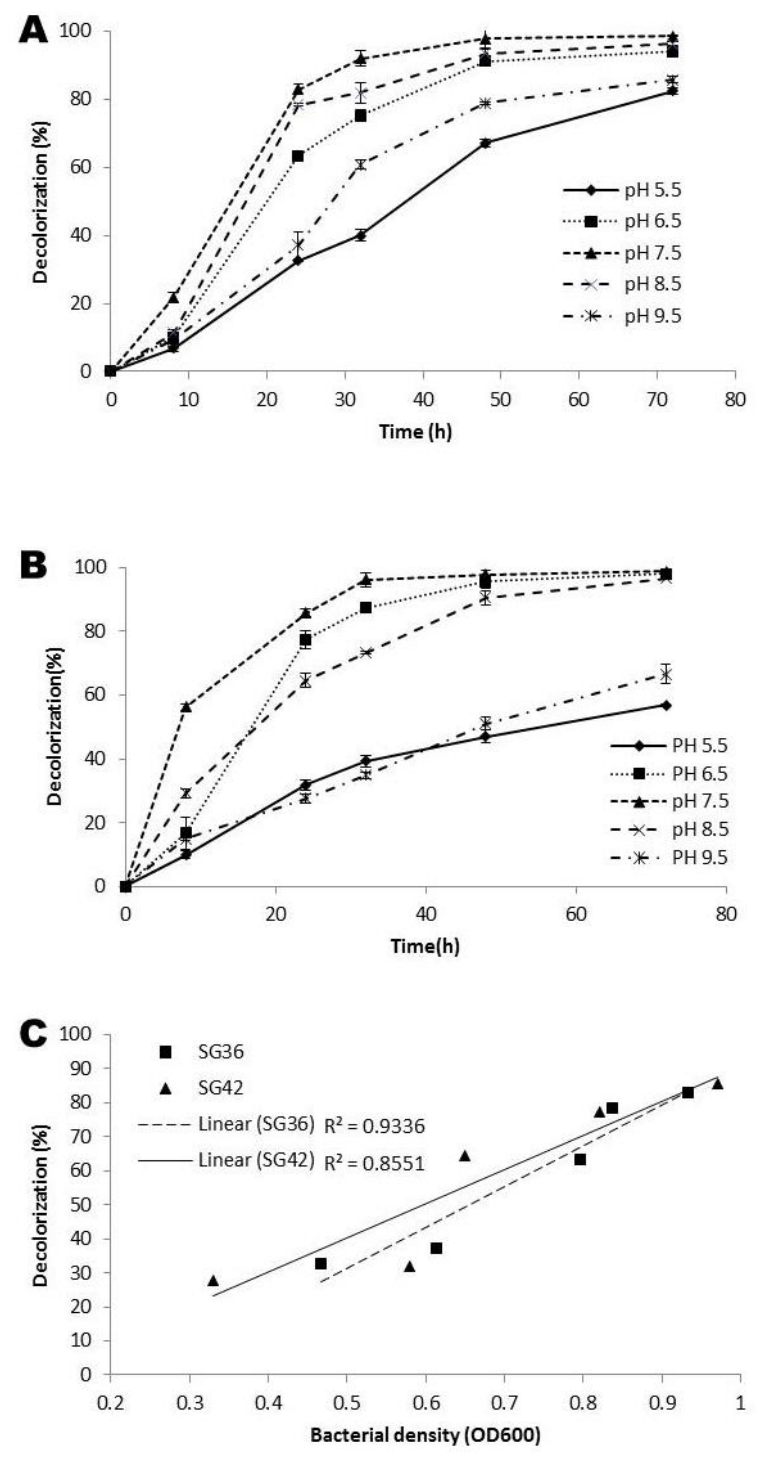

Fig. 2: Decolorization of RY2 by Bacillus sp. SG36 (A) and by Bacillus sp. SG42 (B) at different $\mathrm{pH}$ values. (C) Correlation between decolorization (\%) of RY2, and the cell density of Bacillus sp. SG36 and Bacillus sp. SG42 after 24 $\mathrm{h}$ of incubation

\section{Growth of $V$. radiata in the soil inoculated with strain SG36 and SG42}

The growth of mung bean plants in terms of root/shoot length, root/shoot fresh weight was found to be significantly improved by the both the rhizospheric strains in the noncontaminated as well as RY2 contaminated soils as compared to their respective un-inoculated controls (Table 4). The data shows that the shoot length of mung bean in non-contaminated soil was recorded as $41.3( \pm 3.2) \mathrm{cm}$ which was reduced to $31.8( \pm 1.9) \mathrm{cm}$ in the same soil contaminated with RY2 (500 mg L-1). However, inoculation with both the strains resulted into a significant improvement in the shoot length of the mung bean plants in non-contaminated as well as RY2 contaminated soils. The shoot lengths of the mung bean plants upon inoculation with the strains SG36 and SG42 were observed to be $51.8( \pm 1.7) \mathrm{cm}$ and $44.7( \pm 5.3)$ $\mathrm{cm}$ in non-contaminated soil and $40.1( \pm 2.5) \mathrm{cm}$ and 41.8 $( \pm 2.0) \mathrm{cm}$ in RY2 contaminated soil, respectively (Table 4). Similarly, the inoculation of the strains SG36 and SG42 also resulted in improvement of shoot fresh weight in both the RY2 contaminated as well as non-contaminated soils. The shoot fresh weight of the mung bean plants in noncontaminated soil was recorded as $4.4( \pm 0.27) \mathrm{g} / \mathrm{plant}$, which was reduced to $3.7( \pm 0.21) \mathrm{g} / \mathrm{plant}$ in the same soil contaminated with RY2 $\left(500 \mathrm{mg} \mathrm{L}^{-1}\right)$. The shoot fresh weight of the mung bean plants in response to the inoculation with the strains SG36 and SG42 was observed to be 5.1 $( \pm 0.25) \mathrm{g} /$ plant and $5.2( \pm 0.36) \mathrm{g} /$ plant in non-contaminated soil and $4.6( \pm 0.35) \mathrm{g} /$ plant and $4.3( \pm 0.25) \mathrm{g} /$ plant in RY2 contaminated soil, respectively (Table 4 ). The root length of mung bean in non-contaminated soil was recorded as 17.1 $( \pm 0.4) \mathrm{cm}$, which was reduced to $14.7( \pm 0.9) \mathrm{cm}$ in the RY2 contaminated soil. However, inoculation with both the rhizospheric strains improved root length. The root length of the mung bean plants in response to the inoculation with the strains SG36 and SG42 were observed to be $19.4( \pm 1.0) \mathrm{cm}$ and $19.4( \pm 1.4) \mathrm{cm}$ in non-contaminated soil and $16.5( \pm 1.7)$ $\mathrm{cm}$ and $18.1( \pm 1.3) \mathrm{cm}$ in RY2 contaminated soil, respectively (Table 4). The root fresh weight of the mung bean plants in non-contaminated soil was recorded to be 2.8 $( \pm 0.16) \mathrm{g} /$ plant which was reduced to $2.1( \pm 0.14) \mathrm{g} /$ plant in the same soil contaminated with RY2 $\left(500 \mathrm{mg} \mathrm{L}^{-1}\right)$. The root fresh weight of the mung bean plants in response to the inoculation with SG36 and SG42 were observed to be 3.2 $( \pm 0.22) \mathrm{g} /$ plant and $3.4( \pm 0.34) \mathrm{g} /$ plant in non-contaminated soil and $2.9( \pm 0.26)$ and $2.9( \pm 0.19) \mathrm{g} /$ plant in RY2 contaminated soil, respectively (Table 4). At the end of the experiment, $47.6( \pm 5.9) \%$ of RY2 was found remaining in the un-inoculated RY2 contaminated soil (control). However, only $11.8( \pm 2.7)$ and $14.5( \pm 3.2) \%$ of RY2 was found remaining in the RY2 contaminated soils inoculated with the strains SG36 and SG42, respectively (Table 4) indicating that more than $80 \%$ of the added RY2 dye was decolorized in both the cases.

\section{Discussion}

Contamination of the agricultural soils with synthetic dyes due to the use of different wastewaters for irrigation purpose under water scarce conditions is an emerging challenge because the dyes affect the biological properties of the soils as well as the growth of the crops (Imran et al. 2015). One of the ways to overcome this situation is the isolation, characterization and application of the bacterial strain which have the potential not only to cope with the dyes in soils but 
Table 3: Minimum inhibitory concentration (MIC) of different heavy metals against the bacterial strains Bacillus sp. SG36 and Bacillus sp. SG42

\begin{tabular}{llll}
\hline Metal & Source & MIC $(\mathrm{mM})$ & SG42 \\
\hline & & SG36 & 9.94 \\
Zinc $(\mathrm{Zn})$ & $\mathrm{ZnSO}_{4}$ & 7.65 & 4.83 \\
Lead $(\mathrm{Pb})$ & $\mathrm{Pb}\left(\mathrm{NO}_{3}\right)_{2}$ & 9.66 & 8.45 \\
Cadmium $(\mathrm{Cd})$ & $\mathrm{CdCl}$ & 8.90 & 16.94 \\
Cobalt $(\mathrm{Co})$ & $\mathrm{Co}\left(\mathrm{NO}_{3}\right)_{2}$ & 33.89 & 9.37 \\
Nickle $(\mathrm{Ni})$ & $\mathrm{NiCl}_{2} \cdot 6 \mathrm{H}_{2} \mathrm{O}$ & 8.52 & 28.85 \\
Chromium $(\mathrm{Cr})$ & $\mathrm{K}_{2} \mathrm{Cr}_{2} \mathrm{O}_{7}$ & 21.15 & \\
\hline
\end{tabular}
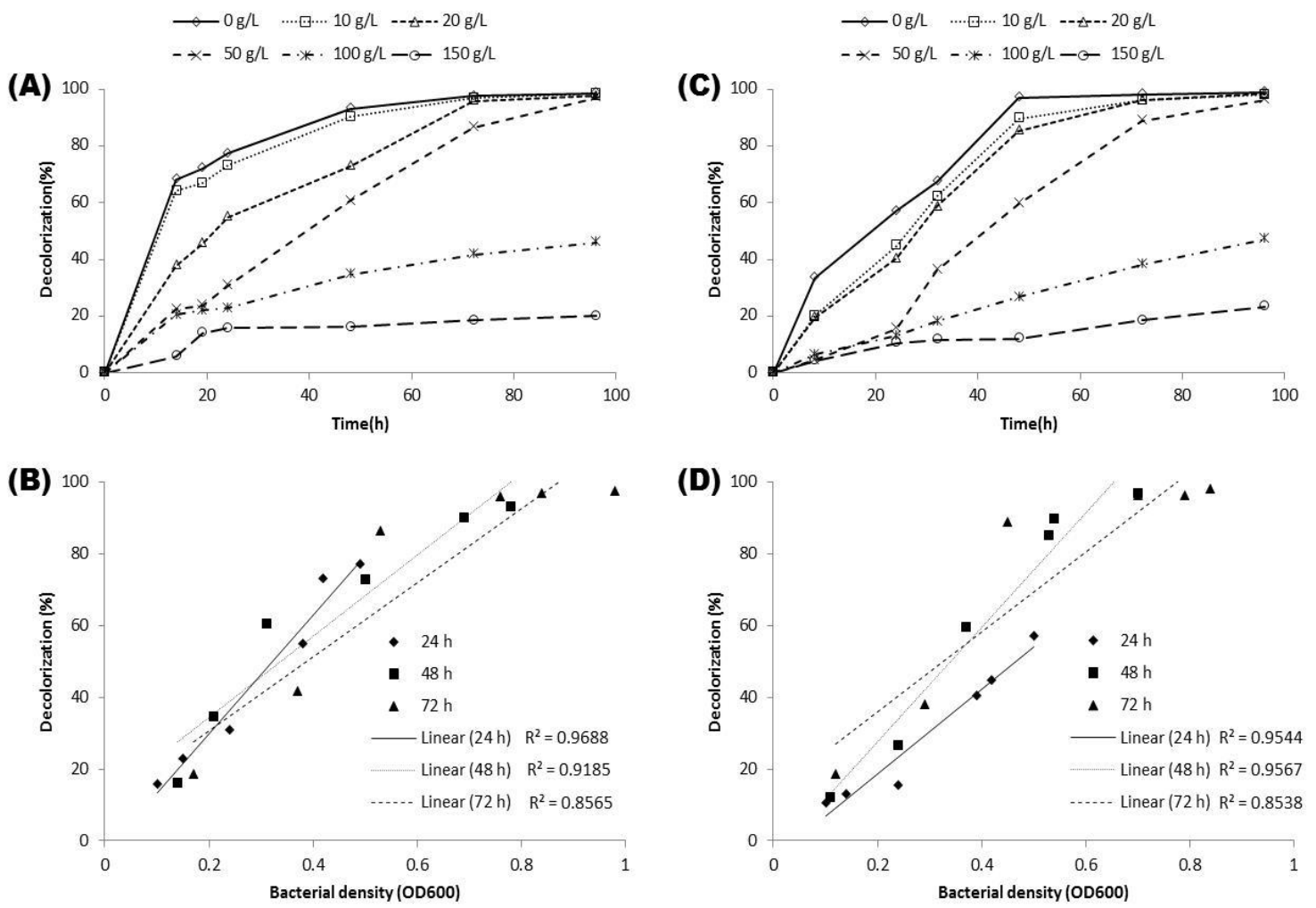

Fig. 3: Decolorization of RY2 by Bacillus sp. SG36 (A) and SG42 (C) in the presence of different salt contents, (B) Correlation between decolorization (\%) of RY2 and the cell density of Bacillus sp. SG36, (D) Correlation between decolorization (\%) of and RY2 and the cell density of Bacillus sp. SG42

also to enhance the growth of plants in soils under stress due to dyes. In the present study, two rhizospheric bacterial strains SG36 and SG42 belonging to genus Bacillus were found to harbor the plant growth promoting (PGP) characteristics including $\mathrm{P}$ solubilization and indole-3-acetic acid (IAA) production in parallel with their potential to decolorize RY2 and other dyes.

Despite that various bacterial strains harbor different PGP characteristics including $P$ solubilization and IAA production (Shahid et al. 2012; Baig et al. 2014; Shahid et al. 2015; Akram et al. 2016; Maqsood et al. 2021) as well as for decolorization of different dyes (Hussain et al. 2013; Abbas et al. 2016; Baig et al. 2019; Imran et al. 2019). However, the present study is unique in that it reports two rhizospheric bacterial strains SG36 and SG42 which possess PGP characteristics together with capability to decolorize dyes. Until now there are very limited studies reporting for such multifunctional bacterial strains having the dual capabilities of plant growth promotion and dyes decolorization (Mahmood et al. 2017; Maqbool et al. 2018). Decrease in $\mathrm{pH}$ during $\mathrm{P}$ solubilization and IAA production by the strains SG36 and SG42 might be due to the release of lowmolecular-weight organic acids (Zaidi et al. 2006; Dwivedi et al. 2011). Hence the isolation of these two Bacillus strains will surely serve as a new addition in potential bioresources harboring such dual capabilities of plant growth and environmental remediation.

In present study, the optimal $\mathrm{pH}$ values for $\mathrm{RY} 2$ decolorization by the strains SG36 and SG42 was found to be 7.5 with a relatively better decolorization at $\mathrm{pH}$ values 
Table 4: Decolorization of reactive yellow 2 in soil and growth of $V$. radiata plants in non-contaminated and RY 2 contaminated soils

\begin{tabular}{|c|c|c|c|c|c|}
\hline \multirow[t]{2}{*}{ Treatments } & \multirow[t]{2}{*}{ Remaining dye (\%) } & \multicolumn{4}{|c|}{ Growth parameters of $V$. radiata } \\
\hline & & Shoot length $(\mathrm{cm})$ & Shoot weight (g/plant) & Root length $(\mathrm{cm})$ & Root weight (g/plant) \\
\hline Non-Contaminated Soil & N/A & $41.3 \pm 3.2 \mathrm{~b}$ & $4.4 \pm 0.27 \mathrm{bcd}$ & $17.1 \pm 0.4 \mathrm{ab}$ & $2.8 \pm 0.16 \mathrm{ab}$ \\
\hline $\begin{array}{l}\text { Non-Contaminated Soil } \\
\text { bioaugmented with strain SG36 }\end{array}$ & N/A & $51.8 \pm 1.7 \mathrm{a}$ & $5.1 \pm 0.25 \mathrm{ab}$ & $19.4 \pm 1.0 \mathrm{a}$ & $3.2 \pm 0.22 \mathrm{a}$ \\
\hline $\begin{array}{l}\text { Non-Contaminated Soil } \\
\text { bioaugmented with strain SG42 }\end{array}$ & N/A & $44.7 \pm 5.3 \mathrm{ab}$ & $5.2 \pm 0.36 \mathrm{a}$ & $19.5 \pm 1.4 \mathrm{a}$ & $3.4 \pm 0.34 \mathrm{a}$ \\
\hline Dye Contaminated Soil & $47.6 \pm 5.9 \mathrm{a}$ & $31.8 \pm 1.9 \mathrm{c}$ & $3.7 \pm 0.21 \mathrm{~d}$ & $14.7 \pm 0.9 \mathrm{~b}$ & $2.4 \pm 0.14 \mathrm{~b}$ \\
\hline $\begin{array}{l}\text { Dye Contaminated Soil } \\
\text { bioaugmented with strain SG36 }\end{array}$ & $11.8 \pm 2.7 b$ & $40.1 \pm 2.5 \mathrm{bc}$ & $4.6 \pm 0.35 \mathrm{abc}$ & $16.5 \pm 1.7 \mathrm{ab}$ & $2.9 \pm 0.26 \mathrm{ab}$ \\
\hline $\begin{array}{l}\text { Dye Contaminated Soil } \\
\text { bioaugmented with strain SG42 }\end{array}$ & $14.5 \pm 3.2 \mathrm{~b}$ & $41.8 \pm 2.0 \mathrm{~b}$ & $4.3 \pm 0.25 \mathrm{~cd}$ & $18.1 \pm 1.3 \mathrm{a}$ & $2.9 \pm 0.19 \mathrm{ab}$ \\
\hline
\end{tabular}
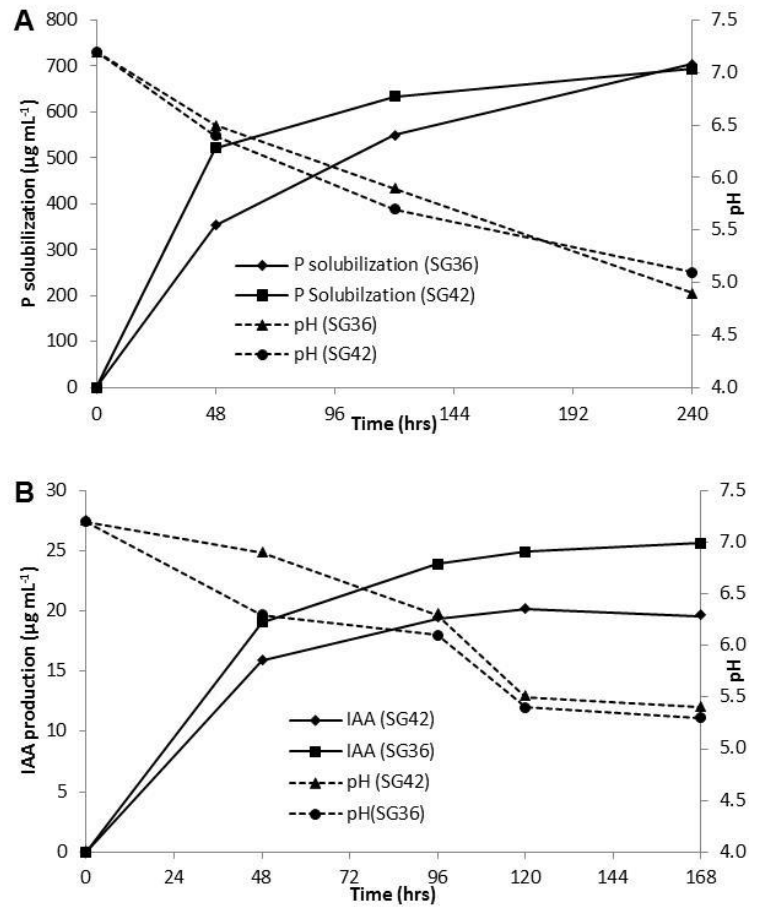

Fig. 4: Plant growth promoting characteristics of the strains Bacillus sp. SG36 and Bacillus sp. SG42. Panel-A reflects phosphate solubilizing activity by the two strains. Panel-B shows indole acetic acid production by the two strains

ranging from 6.5 to 8.5 . This finding is in line with a number of previous studies who reported the neutral to slightly alkaline $\mathrm{pH}$ values as optimal for better decolorization of dyes (Chang et al. 2001; Hussain et al. 2013; Maqbool et al. 2016; Hafeez et al. 2018). pH is an important factor, which affects the growth and activity of microbial populations including the dyes decolorizing bacterial strains (Chan et al. 2011; Hussain et al. 2013; Maqbool et al. 2016; Hafeez et al. 2018). $\mathrm{pH}$ affects the dyes decolorization potential of the bacterial strain either by affecting their growth and survival (Hussain et al. 2013; Anwar et al. 2014; Abbas et al. 2016) or by affecting their enzymatic systems involved in decolorization of dyes (Johansson et al. 2011; Mahmood et al. 2017). It is noteworthy here that the decolorization at different $\mathrm{pH}$ values were found to be correlated with growth at respective $\mathrm{pH}$ values which is showing that the $\mathrm{pH}$ might have affected the growth of the strains resulting into the regulation of decolorization activity accordingly. The strains SG36 and SG42 were also found to tolerate a high level of metal ions as well as $\mathrm{NaCl}$ in media during $\mathrm{RY} 2$ decolorization. Both the strains completely (> 90\%) decolorized RY2 even in the presence of $50 \mathrm{~g} \mathrm{~L}^{-1}$ of $\mathrm{NaCl}$ in the media though the rate of decolorization was decreased over an increase in level of $\mathrm{NaCl}$. The $\mathrm{NaCl}$ levels higher than $50 \mathrm{~g} \mathrm{~L}^{-1}$ adversely affected the RY2 decolorization by both the strains.

Tolerating high levels of metal ions and salts in the media is a beneficial for the dyes decolorizing microbial strains to survive in wastewaters because the wastewaters originating from different industries including textile and tanneries contain considerably high level of metal ions and especially the $\mathrm{NaCl}$ (Imran et al. 2015). Hence, in order to be an effective bioresource for dye decolorization in real textile and tanneries wastewaters, the dyes decolorizing microbial strains should be tolerance to metal ions and $\mathrm{NaCl}$ which is a significant feature of the strains SG36 and SG42. The salt and metal tolerance has also already been reported in a few bacterial strains during decolorization of various different dyes (Moutaouakkil et al. 2003; Zilly et al. 2011; Hussain et al. 2013; Abbas et al. 2016; Hafeez et al. 2018). The adverse effects of very high levels of $\mathrm{NaCl}$ (100 and 150 $\mathrm{g} \mathrm{L}^{-1}$ ) on RY2 decolorization might be due to impact of the salts either on the enzymatic machinery of the microorganisms or on their growth and survival because the organisms may suffer from plasmolysis in such situations (Moutaouakkil et al. 2003; Zilly et al. 2011; Abbas et al. 2016). However, the correlation between the microbial populations of SG36 as well as SG42 and their respective RY2 decolorization in the presence of different $\mathrm{NaCl}$ concentrations are an indicator that the presence of salt might be affecting the growth resulting into regulation of RY2 decolorization accordingly. Nevertheless, there is need to understand the processes responsible for dyes decolorization in response to varying $\mathrm{pH}$ values as well as presence of salts and metal ions by targeting the genes and 
enzymes involved therein.

The strains SG36 and SG42 showed a good potential to promote the growth of mung bean plants in noncontaminated as well as RY2 contaminated soils. A considerable increase in root/shoot length, root/shoot fresh weight of mung bean plants was detected in both of the soils inoculated with these strains in parallel to RY2 decolorization in the soil by both the strains. These data indicated that both the strains have a good potential for the promotion of plant growth even in the soils due to this dye toxicity while both the strains showed a good potential to remediate the soil contaminated with this dye. Previously, Maqbool et al. (2018) reported a $P$. aeruginosa strain ZM130 which showed a reduction in level of $\mathrm{RY} 2$ in the soil along with a considerable promotion of maize growth in that soil. The increase in growth parameters of the mung bean in RY2 contaminated soil might be due to the fact that the strains might have played their role to alleviate the stress by decolorizing the RY2 dye in addition to their plant growth promoting features such as $\mathrm{P}$ solubilization and IAA production.

\section{Conclusion}

The strains SG36 and SG42 might be exploited contemporaneously as efficient bioresources of environmental significance due to their potential to remediate the dyes from the textile wastewater contaminated soils together with their plant growth promoting potentials.

\section{Acknowledgements}

The authors are also grateful to Higher Education Commission (HEC), Pakistan for providing funding for this research under 8206/Punjab/NRPU/R\&D/HEC/2017 and under Indigenous PhD Fellowships (Phase II, Batch V) No. 518-77476-2PS5-033.

\section{Author Contributions}

Yasir Bilal conducted all the experiments and wrote the first draft of the manuscript. Sabir Hussain supervised this research and was involved in planning and supervising the experiments as well as final write-up of the manuscript. Muhammad Shahid, Tanvir Shahzad and Faisal Mahmood helped in conducting the experiments and in improving the write-up of the manuscript.

\section{Conflicts of Interest}

All authors declare that there is no conflict of interest/competing interests in this original article.

\section{Data Availability}

Authors declare that data can be provided on demand.

\section{Ethics Approval}

Not Applicable

\section{References}

Abbas N, S Hussain, F Azeem, T Shahzad, SH Bhatti, M Imran, Z Ahmad, Z Maqbool, M Abid (2016). Characterization of a salt resistant bacterial strain proteus $\mathrm{sp}$. Na6 capable of decolorizing reactive dyes in presence of multi-metal stress. World J Microbiol Biotechnol 32; Article 181

Ahmed F, M Arshad, A Ditta, A Hussain, M Naveed, M Hasnain, Q Nazir (2016). Combining textile effluent wastewater with organic fertilizer for improved growth and productivity of wheat and soil health. $J$ Environ Agric Sci 8:14-20

Akram MS, M Shahid, M Tariq, M Azeem, MT Javed, S Saleem, S. Riaz (2016). Deciphering Staphylococcus sciuri sat-17 mediated antioxidative defense mechanisms and growth modulations in salt stressed maize (Zea mays 1.). Front Microbiol 7; Article 867

Anwar F, S Hussain, S Ramzan, F Hafeez, M Arshad, M Imran, Z Maqbool, N Abbas (2014). Characterization of reactive red-120 decolorizing bacterial strain acinetobacter junii fa10 capable of simultaneous removal of azo dyes and hexavalent chromium. Water Air Soil Pollut 225; Article 2017

Ayed L, A Mahdhi, A Cheref, A Bakhrouf (2011). Decolorization and degradation of azo dye methyl red by an isolated sphingomonas paucimobilis: Biotoxicity and metabolites characterization. Desalination 274:272-277

Baig AM, T Sarwar, L Taj, Y Bilal, E Mazhar, HR Elahi, MM Iqbal, A Rasheed, Z Maqbool, S Hussain (2019). Characterization of a reactive yellow-2 decolorizing zinc tolerant bacterial strain pseudomonas sp. Lt10 isolated from textile industry wastewater. Asian J Agric Biol 7:482-490

Baig KS, M Arshad, A Khalid, S Hussain, MN Abbas, M Imran (2014). Improving growth and yield of maize through bioinoculants carrying auxin production and phosphate solubilizing activity. Soil Environ 33:159-168

Carneiro PA, GA Umbuzeiro, DP Oliveira, MVB Zanoni (2010). Assessment of water contamination caused by a mutagenic textile effluent/ dyehouse effluent bearing disperse dyes. J Hazard Mater 174:694-699

Cervantes FJ, AB Dos Santos (2011). Reduction of azo dyes by anaerobic bacteria: Microbiological and biochemical aspects. Rev Environ Sci Biotechnol 10:125-137

Chacko JT, K Subramaniam (2011). Enzymatic degradation of azo dyes-a review. Intl J Environ Sci 1:1250-1260

Chan GF, NA Rashid, LL Koay, SY Chang, WL Tan (2011). Identification and optimization of novel nar-1 bacterial consortium for the biodegradation of orange ii. Insight Biotechnol 1:7-16

Chang JS, C Chou, YC Lin, PJ Lin, JY Ho, TL Hu (2001). Kinetic characteristics of bacterial azo-dye decolorization by pseudomonas luteola. Water Res 35:2841-2850

Dwivedi S, BR Singh, AA Al-Khedhairy, J Musarrat (2011). Biodegradation of isoproturon using a novel pseudomonas aeruginosa strain js-11 as a multi-functional bioinoculant of environmental significance. J Hazard Mater 185:938-944

Fu Y, ,T Viraraghavan (2001). Fungal decolorization of dye wastewaters: A review. Bioresour Technol 79:251-262

Garzón-Zúñiga MA, AM Sandoval-Villasana, GE Moeller-Chávez (2011) Decolorization of the ao24 azo dye and reduction of toxicity and genotoxicity in trickling biofilters. Water Environ Res 83:107-115

Gordon SA, RP Weber (1951). Colorimetric estimation of indoleacetic acid. Plant Physiol 26:192-195

Hafeez F, H Farheen, F Mahmood, T Shahzad, M Shahid, M Iqbal, S Rasul, H Manzoor, S Hussain (2018). Isolation and characterization of a lead $(\mathrm{Pb})$ tolerant pseudomonas aeruginosa strain hf5 for decolorization of reactive red-120 and other azo dyes. Ann Microbiol 68:943-952

Hasanbeigi A, L Price (2015). A technical review of emerging technologies for energy and water efficiency and pollution reduction in the textile industry. J Clean Prod 95:30-44 
Hussain S, Z Maqbool, S Ali, T Yasmeen, M Imran, F Mahmood, F Abbas (2013). Biodecolorization of reactive black- 5 by a metal and salt tolerant bacterial strain pseudomonas $\mathrm{sp}$. Ra20 isolated from paharang drain effluents in Pakistan. Ecotoxicol Environ Saf 98:331338

Imran M, M Arshad, F Negm, A Khalid, B Shaharoona, S Hussain, SM Nadeem, DE Crowley (2016). Yeast extract promotes decolorization of azo dyes by stimulating azoreductase activity in Shewanella sp. Strain ifn4. Ecotoxicol Environ Saf 124:42-49

Imran M, M Ashraf, S Hussain, A Mustafa (2019). Microbial biotechnology for detoxification of azo-dye loaded textile effluents: A critical review. Intl J Agric Biol 22:1138-1154

Imran M, DE Crowley, A Khalid, S Hussain, MW Mumtaz, M Arshad (2015). Microbial biotechnology for decolorization of textile wastewaters. Rev Environ Sci Biotechnol 14:73-92

Jin XC, GQ Liu, ZH Xu, WY Tao (2007). Decolorization of a dye industry effluent by Aspergillus fumigatus XC6. Appl Microbiol Biotechnol 74:239-243

Johansson HE, MK Johansson, AC Wong, ES Armstrong, EJ Peterson, RE Grant, MA Roy, MV Reddington, RM Cook (2011). BTI1, an azoreductase with ph-dependent substrate specificity. Appl Environ Microbiol 77:4223-4225

Jorquera M, O MARTíNEZ, F Maruyama, P Marschner, M de la Luz Mora (2008). Current and future biotechnological applications of bacterial phytases and phytase-producing bacteria. Microbes Environ 23:182191

Kotoky R, S Nath, DK Maheshwari, P Pandey (2019). Cadmium resistant plant growth promoting rhizobacteria serratia marcescens s2i7 associated with the growth promotion of rice plant. J Environ Sustain 2:135-144

Lade HS, TR Waghmode, AA Kadam, SP Govindwar (2012). Enhanced biodegradation and detoxification of disperse azo dye rubine gfl and textile industry effluent by defined fungal-bacterial consortium. Intl Biodeter Biodegr 72:94-107

Mahmood F, M Shahid, S Hussain, T Shahzad, M Tahir, M Ijaz, A Hussain, K Mahmood, M Imran, SAK Babar (2017). Potential plant growthpromoting strain Bacillus sp. Sr-2-1/1 decolorized azo dyes through nadh-ubiquinone: Oxidoreductase activity. Bioresour Technol 235: $176-184$

Maqbool Z, S Hussain, T Ahmad, H Nadeem, M Imran, A Khalid, M Abid, F Martin-Laurent (2016). Use of rsm modeling for optimizing decolorization of simulated textile wastewater by pseudomonas aeruginosa strain zm130 capable of simultaneous removal of reactive dyes and hexavalent chromium. Environ Sci Pollut Res 23:11224 11239

Maqbool Z, S Hussain, F Mahmood, M Shahid, T Shahzad, T Ahmed, A Sahar, M Imran, Z Ahmad, F Hafeez (2018). Metal-tolerant Pseudomonas aeruginosa strain ZM130 has the potential for concurrent dye decolorization and plant growth promotion. Intl $J$ Agric Biol 20:2621-2631
Maqsood A, M Shahid, S Hussain, F Mahmood, F Azeem, M Tahir, T Ahmed, M Noman, I Manzoor, F Basit (2021). Root colonizing Burkholderia sp. AQ12 enhanced rice growth and upregulated tillering-responsive genes in rice. Appl Soil Ecol 157; Article 103769

Murphy J, JP Riley (1962). A modified single solution method for the determination of phosphate in natural waters. Anal Chim Acta 27:3136

Moutaouakkil A, Y Zeroual, FZ Dzayri, M Talbi, K Lee, M Blaghen (2003). Purification and partial characterization of azoreductase from Enterobacter agglomerans. Arch Biochem Biophys 413:139-146

O'Neill TJ, JD Nguemo, AM Tynan, AN Burchell, T Antoniou (2017). Risk of colorectal cancer and associated mortality in hiv: A systematic review and meta-analysis. J Chem Technol Biotechnol 75:439-447

Pierce J (1994). Colour in textile effluents-the origins of the problem. J Soc Dye Colour 110:131-133

Pikovskaya RI (1948). Mobilization of phosphorus in soil in connection with vital activity of some microbial species. Mikrobiologiya 17:362-370

Roy R, A Fakhruddin, R Khatun, M Islam, M Ahsan, A Neger (2010). Characterization of textile industrial effluents and its effects on aquatic macrophytes and algae. Bangl J Sci Indus Res 45:79-84

Saratale R, G Saratale, D Kalyani, JS Chang, SP Govindwar (2009). Enhanced decolorization and biodegradation of textile azo dye scarlet $\mathrm{R}$ by using developed microbial consortium-GR. Bioresour Technol 100:2493-2500

Shah MP, KA Patel, SS Nair, A Darji (2014). Microbial degradation and decolorization of reactive dyes by Bacillus spp. Etl-1979. Amer $J$ Microbiol Res 2:16-23

Shahid M, S Hameed, A Imran, S Ali JD van Elsas (2012). Root colonization and growth promotion of sunflower (Helianthus annuus 1.) by phosphate solubilizing Enterobacter sp. FS-11. World J Microbiol Biotechnol 28:2749-2758

Shahid M, S Hameed, M Tariq, M Zafar, A Ali, N Ahmad (2015). Characterization of mineral phosphate-solubilizing bacteria for enhanced sunflower growth and yield-attributing traits. Ann Microbiol 65:1525-1536

Syed-Ab-Rahman SF, LC Carvalhais, ET Chua, FY Chung, PM Moyle, EG Eltanahy, PM Schenk (2019). Soil bacterial diffusible and volatile organic compounds inhibit phytophthora capsici and promote plant growth. Sci Total Environ 692:267-280

Tripathi A, S Srivastava (2011). Ecofriendly treatment of azo dyes: Biodecolorization using bacterial strains. Intl $J$ Biosci Biochem Bioinform 1:37-40

Zaidi S, S Usmani, BR Singh, J Musarrat (2006). Significance of Bacillus subtilis strain SJ-101 as a bioinoculant for concurrent plant growth promotion and nickel accumulation in Brassica juncea. Chemosphere 64:991-997

Zilly A, J da Silva Coelho-Moreira, A Bracht, CGM De Souza, AE Carvajal, EA Koehnlein, RM Peralta (2011). Influence of $\mathrm{NaCl}$ and $\mathrm{Na}_{2} \mathrm{SO}_{4}$ on the kinetics and dye decolorization ability of crude laccase from Ganoderma lucidum. Intl Biodeter Biodegr 65:340-344 